\title{
VICTOR SILVA, POETA DECADENTISTA
}

\author{
Fernando Monteiro de Barros (UERJ) \\ fermonbar@uol.com.br
}

\begin{abstract}
Nascido no Rio de Janeiro e radicado no Rio Grande do Sul a partir de 1897, onde exerceu a função de diretor da Biblioteca Pública do Estado de 1907 até a sua morte, Victor Silva (1865-1922) afigura-se um exemplo de como as etiquetas classificatórias acabam por não dar conta da pluralidade de acentos que vibram na produção poética do período finissecular oitocentista até a Belle Époque. Embora em vida tenha publicado seus poemas regularmente em periódicos da época, como as revistas cariocas Kosmos e Renascença, sua obra poética reunida só saiu postumamente, em um único volume, Victorias (1924), livro eclipsado pela febre modernista recémdeflagrada no país.
\end{abstract}

Nos decênios que vão do final do século XIX ao começo do século XX, a poesia brasileira possui a marca do ecletismo e do hibridismo estético. Os estilos finisseculares dezenovescos, o Parnasianismo e o Simbolismo, de origem francesa, não chegaram ao Brasil de forma ortodoxa e purista, mas sim marcados por uma contaminação estilística recíproca em que também se deixa entrever, como uma serpente passeando no jardim, o Decadentismo, além de residuais sobrevivências do Romantismo.

Já na França, seu país de origem, estes estilos apresentam matrizes comuns em seus escritores-fundadores. Théophile Gautier (1811-1872), no famoso prefácio ao romance Mademoiselle de Maupin, de 1835 , ao propor a independência da arte em relação ao critério de utilidade, consolida o ideal estético da arte pela arte, que se constituirá num dos traços definidores da poética parnasiana; no mesmo prefácio, ao reivindicar o divórcio entre a arte e a moral, Gautier já lança as sementes do estilo decadentista que florescerá várias décadas depois, igualmente imbuído da premissa da autonomia suprema da arte. Acrescente-se a isso o fato de Gautier ter integrado a antologia que deu início ao Parnasianismo, Le Parnasse Contemporain, em seus dois primeiros volumes, 1866 e 1871, da qual, aliás, também participaram nomes como Charles Baudelaire (1821-1867), 
Paul Verlaine (1844-1896) e Stéphane Mallarmé (1842-1898), poetas tutelares tanto do Decadentismo quanto do Simbolismo.

Parnasiano convicto, segundo João Pinto da Silva, autor da História Literária do Rio Grande do Sul, que o conheceu pessoalmente, Victor Silva, de forma paradoxal, manifestava veemente desprezo pelos poetas simbolistas (SILVA, 1930, p. 201), enquanto, ao mesmo tempo, revelava-se entusiasmado e fascinado pelo exemplar do livro Les Fleurs du Mal (1857), de Charles Baudelaire, por ele todo sublinhado e rabiscado com comentários elogiosos ao fim de cada poema, como "prodigioso!", "belíssimo!", "magnífico!", “estupendo!", "extraordinário!" e, sob o primeiro soneto do "Un Fantome" ("Um Fantasma”), a exclamação: "belo e sombrio!” (Idem, p. 204).

Juntos, esses dois adjetivos, belo e sombrio, usados pelo poeta para manifestar seu elogio ao poema de Baudelaire, sintetizam, na literatura do século XIX, uma linhagem que parece ter início com as concepções estéticas do norte-americano Edgar Allan Poe (18081849), famoso por seus contos macabros, porém determinante para as tendências que irão reger a poesia europeia da segunda metade do século. Para Poe, ao contrário dos poetas românticos, mais comprometidos com a vontade de expressão do que com o tratamento formal da poesia, "a Beleza é a única província legítima do poema" (POE, 1985 , p. 104), beleza poética esta tanto mais pungente quanto mais aliada à melancolia e à morte (Idem, p. 107). Esta premissa, defendida por Poe e consolidada na França por Baudelaire, que o traduziu e divulgou, irá dar o tom da estética do Decadentismo, surgida na década de 1880 e marcada pela chancela desses dois vetores: o belo, pelo culto supremo da Arte e da Beleza dissociados de qualquer finalidade de cunho moral ou utilitário, bem como pela eleição do artifício como culminância do esteticismo, e o sombrio, pelo culto decadentista do doentio, do malsão, do perverso, do mórbido e do macabro, em signos perpassados pelas imagens demoníacas da ruína e da morte (PRAZ, 1988, p. 47).

Destarte, malgrado seu desdém pelo Simbolismo, irmãogêmeo do Decadentismo, Victor Silva apresenta, em vários de seus sonetos parnasianamente impecáveis, como poeta exigentíssimo que era, "nunca achando perfeitos os seus versos, por mais irrepreensíveis que fossem" (PRATES, 1951, p. 5), ao lado do esplendor re- 
quintado de suas estrofes, a nota inquietante do macabro, como no soneto "Solar Encantado" (SILVA, 1924, p. 66-67):

Só, dominando no alto a alpestre serrania,

Entre alcantis, e ao pé de um rio majestoso,

Dorme quedo na névoa o solar misterioso,

Encerrado no horror de uma lenda sombria.

Ouve-se à noite, em torno, um clamor lamentoso,

Piam aves de agouro, estruge a ventania,

E brilhando no chão por sobre a relva fria,

Correm chamas sutis de um fulgor nebuloso.

Dentro um luxo funéreo. O silêncio por tudo...

Apenas, alta noite, uma sombra de leve

Agita-se a tremer nas trevas de veludo...

Ouve-se, acaso, então, vaguíssimo suspiro,

E na sala, espalhando um clarão cor de neve,

Resvala como um sopro o vulto de um vampiro.

Em alexandrinos clássicos, todos rigorosamente acentuados na sexta sílaba, com cesura e hemistíquios bem demarcados e a presença de várias rimas raras, evidenciando apuradíssimo cuidado formal, conforme as prescrições de Poe e Baudelaire e presente nas poéticas finisseculares, posto que mais fortemente identificado com o Parnasianismo, o soneto de Victor Silva funde poéticas distintas. Além do esteticismo requintado, o poema apresenta ressonâncias do Romantismo em sua faceta gótica, como, aliás, já fizera o poeta parnasiano Alberto de Oliveira, cujo poema "Fantástica", de 1884, apresenta alguns versos que ecoam no soneto de Victor Silva ("E o silêncio por tudo! Nem de um passo / Dão sinal os extensos corredores"), atestando o traço residual romântico em nossa poesia parnasiana.

O quarteto inicial do poema inscreve o "solar misterioso" do título na categoria do espaço gótico do castelo mal-assombrado, "encerrado no horror de uma lenda sombria", ao mesmo tempo em que destaca a vinculação deste espaço com a aristocracia, classe arruinada e fantasmática após a consolidação do poder da burguesia no final do século XVIII. Hieraticamente, o solar está no alto das montanhas, "alpestre serrania", entre "alcantis", ou seja, despenhadeiros escarpados, que lembram o cenário do castelo de Drácula. O "rio majestoso" ao seu pé inscreve-o na altivez aristocrática que sobranceiramente ostenta. No segundo quarteto, a presença de elementos demonía- 
cos (conforme as "imagens demoníacas" da "teoria do sentido arquetípico" proposta por Northrop Frye: "o mundo do pesadelo", "das ruínas e catacumbas" e dos "vastos, ameaçadores, brutos poderes da natureza", FRYE, 1973, p. 148), associados à natureza assustadora em torno do solar, enfatizam a atmosfera gótica do cenário exterior. No primeiro terceto, ao observarmos agora o foco no cenário interior, deparamo-nos com a rubrica do "luxo funéreo", sintagma que conjuga o belo e o sombrio, e que dá a tônica decadentista à segunda metade do poema, na qual o soturno das trevas alia-se à beleza artística do veludo e onde, enclausurado como Des Esseintes (protagonista do romance decadentista Às avessas, de J. K. Huysmans, de 1884) em sua mansão, "agita-se a tremer", exalando "vaguíssimo suspiro", o nevrosado e melancólico vampiro de Victor Silva, paradoxal no seu resvalar "como um sopro", que apenas deixa entrever, de forma fugidia, o seu vulto, o que o inscreve ao mesmo tempo nas categorias de presença e ausência (AGAMBEN, 2007, p. 97), espaço fronteiriço que rasura o binarismo da doxa cientificista do século XIX. Ao rodopiar em seu movimento deslizante, o vampiro produz um efeito cromático e estético, "espalhando um clarão cor de neve", e isso tudo "na sala", que é, no âmbito privado, o espaço do espetáculo social. Deste modo, ao mesmo tempo misantropo e elegante, o vampiro do soneto apresenta-se como um dos pertencentes à estirpe dos dândis, personagens principais da cena decadentista.

É principalmente pelo viés do gótico que se dá o liame entre Romantismo e Decadentismo, liame este proficuamente analisado por Mario Praz $(1988,1996)$, um dos principais teóricos da estética de Wilde e Huysmans. O gótico literário de fins do século XVIII e começo do século XIX é um estilo que, mais que nenhum outro talvez, caracteriza-se, além da atmosfera aterrorizante, pelo cenário e pela decoração (WILLIAMS, 1995, p. 14), que lhe conferem um caráter de teatralidade e simulacro. Cristalizado em clichês que chegaram até o nosso século com os vampiros e castelos mal-assombrados do cinema e da televisão, o esteticismo gótico, antes de sua popularização midiática, já era massificado nos folhetins ingleses de meados do século XIX e no teatro de variedades e vaudeville franceses da década de 1820 (LECOUTEUX, 2005, p. 21), que popularizaram a tradução francesa do conto The Vampyre (1819) de John Polidori, texto-marco da literatura do gênero. Assim, ao fazerem uso de ima- 
gens já em fins do século XIX tão marcadas pelo chavão, os escritores decadentistas não apenas obtinham o tom mórbido de que tanto gostavam como também exibiam acintosamente as marcas da pura impostação de seu texto literário, tecido sob o signo do artifício.

Curiosamente, assim como o vampiro de seu poema, Victor Silva, "amigo da solidão, era um discípulo fiel de Heredia e de Leconte de Lisle, burilando com grande perfeição e apuro - às vezes durante meses - seus álgidos sonetos, que nunca desejou publicar em livro" (GÓIS, 1960, p. 381), em atitude análoga a Des Esseintes em seu isolamento, assim como também aos próprios escritores decadentistas, desdenhosos do grande público. Em "Prelúdio" (SILVA, 1924, p. 9), soneto de abertura de Victorias, o poeta proclama que leitores néscios

\footnotetext{
Dirão que esplendem com serena calma Porém, sem vida, os meus versos protervos; Mas, eu que os sinto cheios de minha alma,

Leio-os, e neles, palpitante e exangue, Escuto o grito horrível de meus nervos E aspiro o cheiro de meu próprio sangue.
}

A metalinguagem também está presente em dois outros sonetos do livro de 1924, "Acrobata" ("O povo aplaude e ri; mal sabe o povo, entanto, / Que hirto, gelado o sangue, e abafando o meu pranto, / Transpus neste soneto um círculo de facas") (Idem, p. 45) e "Em Ouro" ("E ao jeito de um ourives florentino / Bordo o soneto em filigrana de ouro") (Idem, p. 47), cujos versos, aqui transcritos, apontam para o eixo paradoxal da poesia deste autor que reúne tanto a ourivesaria da forma quanto a dramaticidade visceral do tema. "A poesia de Victor Silva é em grosso parnasiana, mas dela ressumam também tons de exceção, macabros, decadentes, a denunciar a influência de Poe e Baudelaire" (RAMOS, 1967, p. 242), diz o crítico Péricles Eugênio da Silva Ramos, ao ratificar o elemento gótico-decadentista da obra do poeta.

Embora seja sempre enfatizada a ligação quase simbiótica do Simbolismo com o Decadentismo, há muitos pontos de convergência entre este e o Parnasianismo. Para o crítico Alfredo Bosi, "é apenas de grau a diferença entre o parnasiano e o decadentista brasileiro: naquele o culto da Forma; neste a religião do Verbo" (BOSI, 1999, 
p. 268). Da mesma forma, ressalta Cassiana Carollo que "determinadas posturas inauguradas pelo parnasianismo foram legadas aos decadistas e simbolistas, também defensores do ideal da arte pela arte, e de todo um comportamento esteticista envolvendo o conceito de beleza e de produção artística" (CAROLLO, 1980, p. 1). Não nos esqueçamos que "a concepção de uma arte expressando os efeitos dos tempos de decadência remonta a Théophile Gautier" (Idem, p. 5), como já dito, um dos principais fundadores do Parnasianismo francês, "que emprega o termo em 1869 em um prefácio de sua autoria às Flores do Mal" (Ibidem).

No soneto "Alucinação" (SILVA, 1924, p. 26-27), temos mais um exemplo do traço goticizante da poesia de Victor Silva, acrescido do tema, decadentista por excelência, da "mulher fatal":

\author{
No baile, esbelta e branca, o seu olhar nevoento \\ Fitou-me; e como à pluma arrasta a ventania, \\ Insano amor, paixão de morte, num momento, \\ Minha alma arremessou num inferno de agonia... \\ Falei-lhe, foi delírio e clamor de lamento; \\ Quis vê-la em seu palácio, e a Esfinge altiva e fria, \\ Com a sombra de um sorriso e um vago gesto lento, \\ "O seu palácio, diz, somente a morte o abria." \\ Sigo-a perdido e louco, em seu jardim me oculto, \\ Vejo-a entrar no castelo e sumir-se o seu vulto; \\ Tento alcançá-la, corro; acho aberta uma porta, \\ Entro, a sala é mortuária, em torno o crepe esvoaça. \\ - "Onde a Senhora? - Indago a um fâmulo que passa. \\ - "Repousa em terra santa. Há dous dias que é morta"...
}

Aqui, a femme fatale é, ao mesmo tempo, fantasma gótico e esfinge parnasiana, "altiva e fria", em um poema onde a paixão e o erotismo são interditados, já que no Decadentismo apenas têm lugar os gozos mentais e estéticos. O primeiro verso do último terceto conjuga novamente os semas do belo (o crepe que esvoaça em torno) e do sombrio (a sala mortuária), corroborando o eixo paradoxal proposto por Edgar Allan Poe, em um soneto onde o assunto, que lembra o de uma balada medieval, é revestido pelo requinte dos versos alexandrinos de rimas raras em sua maioria. 
Esta dialética do gótico-parnasiano, ou, como analogamente podemos afirmar, do Decadentismo, também pode ser apontada em vários outros poemas de Victor Silva, como "Fogo-Fátuo" "Na treva e no pavor das noites taciturnas...") (Idem, p. 28), "Jettatura" ("E na treva, a gemer, sob a luz de teus olhos, / Vou descendo os degraus de minha catacumba.") (Idem, p. 31) e "Sacrilégio" (Idem, p. 32-33), onde percebemos o cumprimento da lição estética de Poe, que afirmara não existir tema mais poético no mundo do que a ruína de uma bela mulher (POE, 1985, p. 107):

Morreu. Brilha na alcova um círio fumarento:

Nua, solto o cabelo, inteiriçada e fria,

Dentro do esquife como um ídolo agourento

Resplandece ao fulgor de acesa pedraria.

O olhar gelado exala um fluido luarento...

Arde em rolos o incenso; estruge a ventania;

É noite; a neve cai... e um triste encantamento

Circula na mudez da câmara sombria.

Chego, mudo, a tremer, do seu féretro junto,

Desvaira-me o esplendor dessa carne querida,

Seduz-me a tentação do seu corpo defunto...

E o mesmo ardente anelo, o mesmo ideal transporte,

Toda a louca paixão com que eu a amei em vida

Sinto-a com o mesmo ardor na volúpia da morte...

O Decadentismo foi, sobretudo, um estilo em que a arte se voltava para si própria - para defini-lo, a expressão "arte sobre a arte" estaria mais de acordo do que "arte pela arte". No texto basilar desta estética, o romance Às avessas (1884) de J.-K. Huysmans, os capítulos tratam de várias modalidades da arte, citando exaustivamente obras artísticas e literárias da cultura ocidental até a sua época. Similarmente, na obra poética de Victor Silva, encontramos vários sonetos que versam sobre artistas da cultura ocidental, como "Dante", "Chopin", "Beethoven", bem como um grupo de quatro sonetos reunidos sob o título "Tentação de Santo Antão", em evidente diálogo intertextual com o texto de Gustave Flaubert preferido pelos decadentistas, La Tentation de Saint Antoine, de 1874 (PRAZ, 1996, p. 150). Do mesmo modo, percebemos tal rubrica na série de sonetos intitulados "Em Ouro", "Em Prata", "Em Mármore", "Em Bronze", "Em Pedra" e "Em Seda", onde o poeta, respectivamente, trata da 
metalinguagem poética ("o soneto em filigrana de ouro", já citado), de uma urna grega em prata, da estátua em mármore do Moisés de Michelangelo, do alto-relevo de uma mulher-fatal em uma moeda de bronze, de um ídolo de pedra e de uma gravura tecida (ou talvez pintada) sobre a seda, cujos versos transcrevemos (SILVA, 1924, p. 5657):

\author{
Na seda iriante, o Artista, em cores luminosas, \\ Pôs um bosque pagão sob a névoa da lua, \\ É uma ilha da Grécia, o argênteo mar flutua, \\ E enche a selva um rumor de vozes misteriosas... \\ Bailam ninfas a rir; o perfume tressua... \\ Súbito, um Fauno exsurge entre as ramas frondosas, \\ E, oblíquo o olhar, espreita uma Dríade nua, \\ Que, alva, dorme ao luar, sob um toldo de rosas. \\ Numa colina, ao fundo, anda a hirsuta figura \\ De um deus que é como um bode, atento, a avena pura \\ Sopra, e a música suave agita a espessa mata, \\ Mais longe, sobre o mar, nas ondas resvalando, \\ Em gráceis grupos vão as sereias cantando \\ Com olhos de esmeralda e de caudas de prata.
}

É curioso observar que Silva, em sua proclamada ojeriza pela estética simbolista, apresente aqui o mesmo cenário e criaturas de "L'Après-midi d'un Faune" ("A Tarde de um Fauno"), poema de Stéphane Mallarmé, um dos principais nomes do Simbolismo francês, que certamente deve ter influenciado o grupo constituído em 1891 em torno da Folha Popular de que faziam parte os decadentistas-simbolistas brasileiros B. Lopes, Emiliano Perneta, Oscar Rosas e Cruz e Sousa, que usaram a ilustração de um fauno como insígnia, em sua batalha pela adaptação do Decadentismo-Simbolismo no Brasil (CAROLLO, 1980, p. 213). Contudo, enquanto o poema de Mallarmé singulariza-se pela indeterminação do conteúdo, de significado fugidio, os versos de Victor Silva são claros em seu descritivismo parnasiano, em que avulta o gosto pelo ornamental e a índole plástica, visual, de sua escrita artística. Nas palavras de Homero Prates, "Victor Silva era um torturado da Forma, um doente da Beleza que levava semanas e até meses trabalhando um soneto que, em compensação, lhe saía sem um defeito" (PRATES, 1951, p. 5). 
Seu poema "Múmias" (SILVA, 1924, p. 116-117) retoma a clave da beleza sombria, na qual se conjuga o horror das evocações da morte ao esplendor e requinte aristocráticos da civilização egípcia:

\author{
Imagino-as no horror dos hipogeus mortuários, \\ Mirradas sob o pó das gomas aromosas, \\ Entre emblemas da Morte e vasos cinerários \\ Esparsos na mudez das alas tenebrosas. \\ Na sombra, em longa fila, os gênios funerários \\ Fitam com olhar de espanto as múmias silenciosas, \\ Estreladas de anéis e acesos relicários \\ Onde um Íbis feral abre as asas radiosas... \\ $\mathrm{O}$ ar, em torno, sufoca; uma estranha figura \\ Soluça desolada a um canto, de mãos juntas; \\ Foge a traça senil que nos túmulos medra... \\ E no basalto negro a rubra iluminura \\ Dos hieróglifos conta as tradições defuntas \\ E o sombrio esplendor dos séculos de pedra.
}

Os versos finais apontam para o mote, decadentista por excelência, da decadência e do esboroamento de épocas e civilizações, o "tom crepuscular" (MORETTO, 1989, p. 32) que valoriza a beleza "da finitude das coisas" (Ibidem), ditando, em uma mirada especular, o acento saturnino que permeia o fim de toda uma era prestes a desmoronar com o advento da iconoclastia modernista. Tal mote também está presente na derradeira estrofe do poema final do livro de Victor Silva, "Esfinge" (SILVA, 1924, p. 119):

Impérios colossais, potestades divinas,

Patriarcas e reis de infinda majestade,

Tudo desfez-se em pó e esboroou-se em ruínas...

O fausto fúnebre que permeia as imagens cultivadas pelos decadentes, onde a ideia da morte está associada à espetacularização, fruto de um fazer artístico refinado e deliquescente, parece servir de consolo à aproximação da onda modernizadora que arrasará com o ornamentalismo nas artes e no cenário das cidades, onde belíssimas construções art-nouveau serão demolidas para darem lugar a prédios funcionais e rigorosos em seu despojamento estético. Metáfora de sua criação poética, o vampiro enclausurado do poema de Victor Silva sobrevive no solar-estufa cercado de ruína e esplendor, imerso no 
sortilégio exclusivo da arte e infenso, assim, à insipidez dos costumes americanos de nosso tempo. Mesmo que, como seu autor, esteja atravessando esquecido o trânsito vertiginoso dos séculos. Os versos de "Ecce Homo" ratificam a postura dândi do poeta aqui estudado: "Segue. Rude é a jornada ao País da Beleza. / Vai só, alheio à dor, sem ódio e sem piedade..." (Idem, p. 60).

Há outros aspectos que também poderíamos assinalar na poesia de Victor Silva, como a obsessão pelo sangue presente em vários de seus versos e sintetizada no soneto "Sonho de Canibal" ("Sangue! Sangue! e oh! volúpia, a rolar no deserto / De sangue...") (Idem, p. 115), bem como alguns sonetos que apresentam as forças titânicas da natureza, marcadas pela clave do sinistro e do tenebroso, como nestes versos do poema "A Gruta dos Aflitos" (Idem, p. 72), de cariz muito mais romântico do que decadentista, pois, como se sabe, o Decadentismo desprezava a rubrica do natural em prol do culto ao artifício:

\author{
Um pavor glacial assombra a esconsa gruta \\ Onde a luz mal lampeja; a água, em fio, que medra \\ Nas penhas, a escorrer como um pranto, se escuta \\ Gota a gota a pingar das paredes de pedra. \\ Aves de horrendo aspecto em lentos rodopios \\ Voam pesadas no ar com lúgubre regougo, \\ E nas fendas da rocha os corujões sombrios \\ Escancaram na treva as pupilas de fogo.
}

Assim, concluímos por ora nossas reflexões sobre Victor Silva, assinalando a validade de se trazer às discussões acadêmicas contemporâneas, e ao conhecimento mesmo dos leitores de poesia, a obra cintilante e paradoxal deste poeta esquecido, em que se pode vislumbrar tanto as tendências finisseculares das estéticas oitocentistas como também as reverberações do Decadentismo em nossa produção poética da Belle Époque.

\title{
REFERÊNCIAS BIBLIOGRÁFICAS
}

AGAMBEN, Giorgio. Estâncias - a palavra e o fantasma na cultura ocidental. Trad. Selvino José Assmann. Belo Horizonte: UFMG, 2007. 
BAUDELAIRE, Charles. As flores do mal. Edição Bilíngue. Trad. Ivan Junqueira. Rio de Janeiro: Nova Fronteira, 1985.

BOSI, Alfredo. História concisa da literatura brasileira. 36. ed. São Paulo: Cultrix, 1999.

CAROLLO, Cassiana Lacerda. Decadismo e simbolismo no Brasil: crítica e poética. Rio de Janeiro: Livros Técnicos e Científicos; Brasília: INL, 1980.

FRYE, Northrop. Anatomia da crítica. Trad. Péricles Eugênio da Silva Ramos. São Paulo: Cultrix, 1973.

GÓIS, Fernando. Panorama da poesia brasileira. Vol. V: O Pré-Modernismo. Rio de Janeiro: Civilização Brasileira, 1960.

HUYSMANS, J.-K. Às avessas. Trad. José Paulo Paes. São Paulo: Cia. das Letras, 1987.

LECOUTEUX, Claude. História dos vampiros: autópsia de um mito. Trad. Álvaro Lorencini. São Paulo: UNESP, 2005.

MALLARMÉ, Stéphane. Poesias. Trad. José Augusto Seabra. Lisboa: Assírio \& Alvim, 2005.

MORETTO, Fulvia M. L. Caminhos do decadentismo francês. São Paulo: Perspectiva/Universidade de São Paulo, 1989.

OLIVEIRA, Alberto de. Melhores poemas. Seleção Sânzio de Azevedo. São Paulo: Global; Rio de Janeiro: Academia Brasileira de Letras, 2007.

POE, Edgar Allan. A filosofia da composição. In: Poemas e ensaios. Trad. Oscar Mendes e Milton Amado. Rio de Janeiro: Globo, 1985, p. 104.

PRATES, Homero. Poetas esquecidos. Vítor Silva - Vitórias - Traços para um ensaio. Jornal do Comércio, Rio de Janeiro, 30 de setembro de 1951, p. 5.

PRAZ, Mario. A carne, a morte e o diabo na literatura romântica. Trad. Philadelpho Menezes. Campinas: UNICAMP, 1996.

. El pacto con la serpiente. Trad. Ida Vitale. México: Fondo de Cultura Econômica, 1988. 


\section{FACULDADE de FoRMAÇÃO de PROFESSORES}

RAMOS, Péricles Eugênio da Silva. Poesia parnasiana: antologia. São Paulo: Melhoramentos, 1967.

SILVA, João Pinto da. História literária do Rio Grande do Sul. 2. ed. Porto Alegre: Livraria do Globo 1930.

SILVA, Victor. Victorias. Porto Alegre: Barcellos, Bertaso \& Cia. I Livraria do Globo, 1924.

WILLIAMS, Anne. Art of darkness: a poetics of Gothic. Chicago: The University of Chicago Press, 1995. 